\title{
Precancerous Tissue Graft
}

National Cancer Institute

\section{Source}

National Cancer Institute. Precancerous Tissue Graft. NCI Thesaurus. Code C122937.

The transfer of premalignant tissue from one anatomic site to another, within the same individual or between individuals. 